\title{
Diet-induced acidosis: is it real and clinically relevant?
}

\author{
Joseph Pizzorno $^{1 *}$, Lynda A. Frassetto ${ }^{2}$ and Joseph Katzinger ${ }^{3}$ \\ ${ }^{1}$ PO Box 25801, Bastyr University, Seattle, WA 98165, USA \\ ${ }^{2}$ Division of Nephrology, 12 Moffitt CTSI Clinical Research Center, University of California, San Francisco, CA, USA \\ ${ }^{3}$ Salugenecists, 19531 7th Avenue NE, Shoreline, WA 98155, USA
}

(Received 5 November 2008 - Revised 6 July 2009 - Accepted 21 October 2009 - First published online 15 December 2009)

The concept of diet-induced 'acidosis' as a cause of disease has been a subject of interest for more than a century. The present article reviews the history of our evolving understanding of physiological $\mathrm{pH}$, the physiological support for the concept of 'acidosis', the causes of acidosis, how it is recognised, its short-term effects as well as the long-term clinical relevance of preventative measures, and the research support for normalisation of pH. Further, we suggest differentiation of the terms 'acidosis' and 'acidaemia' as a way to resolve the conflation of these topics which has led to confusion and controversy. The available research makes a compelling case that diet-induced acidosis, not diet-induced acidaemia, is a real phenomenon, and has a significant, clinical, long-term pathophysiological effect that should be recognised and potentially counterbalanced by dietary means.

Acid-base equilibrium: Acidosis: Diet-induced acidosis: Metabolic acidosis: Endogenous acid production: Renal net acid excretion

\section{Historic overview}

The study of acid-base equilibrium and its relationship to the diet and disease has been a subject of considerable speculation for at least several centuries. But, before the 19th century, little was known about the concepts of acids and bases, and no means were available to quantify the acid or alkaline load of foods, or of the $\mathrm{pH}$ of physiological processes. Not until the second half of the 19th century did nutritional science began to develop, and the chemical components of food start to be analysed. Henry Clapp Sherman's book in 1919, [The] Chemistry of Food and Nutrition, describes the history of nutritional studies performed up to that date (Sherman was the first to quantify nutritional acid load in 1912).

During the next half century, a number of clinical practitioners outside of academia began to observe health improvements in their patients from consuming unprocessed raw fruits and vegetables, instead of the processed food which were increasingly becoming the standard fare, and developed the concept that life is an equilibrium between acid and base. However, it was not until the $1960 \mathrm{~s}$ that input-output acid-base balance studies were performed for the first time in healthy adults and patients with chronic renal acidosis ${ }^{(1,2)}$. There is still a great deal of debate on how to define acids and bases. In the 1980s, Peter Stewart challenged traditional thought and mathematically determined that hydrogen ion and bicarbonate concentrations were dependent variables. He considered the independent variables, which by definition would determine the dependent variables, to be the strong ion difference (the difference in the net charge of cations and anions fully dissociated in solution), the partially dissociated weak acids (albumin, phosphate), and the partial pressure of carbon dioxide $\left(\mathrm{P}_{\mathrm{CO} 2}\right)$ of the solution. While a full discussion of the implications of the differences between theories is beyond the scope of the present paper, of significance is the lack of consensus in the fundamental understanding of the mechanisms, as well as the practical applications of acid-base chemistry in physiological systems. A lengthy review published in January 2008 emphasises this point $t^{(3)}$, and excellent reviews of acid-base history are available ${ }^{(4,5)}$.

\section{Definitions: acidosis, acidaemia and diet-induced acidosis}

For the purposes of the present review, some definitions are in order, though it should be clear that most definitions are not universally accepted. The term acidosis is often used interchangeably with the term acidaemia, with the latter referring to a blood $\mathrm{pH}$ of less than 7.35. Correctly used, the term acidosis refers to a process, or a trend toward acidaemia, without necessarily reaching a $\mathrm{pH}$ of less than $7 \cdot 35$, or actual acidaemia. The concentration of $\mathrm{H}^{+}$in blood plasma and various other body solutions is among the most tightly regulated variables in human physiology. Acidosis only becomes acidaemia when compensatory measures to correct it fail. To illustrate the difference between acidosis and acidaemia, take the following example: two processes

Abbreviations: NAE, net acid excretion; NEAP, net endogenous acid production; PRAL, potential renal acid load.

* Corresponding author: Dr Joseph Pizzorno, fax +1 206368 8570, email drpizzorno@salugenecists.com 
occurring simultaneously in the same individual, such as a respiratory acidosis combined with a metabolic alkalosis. In this case, if the respiratory trend toward acidosis is greater than the metabolic trend, a $\mathrm{pH}$ of less than 7.35 may be reached, and would be considered acidaemia, despite the presence of a metabolic alkalosis. The intensity of each 'process' will determine the $\mathrm{pH}$, but the terms themselves (acidosis, alkalosis) do not indicate a certain $\mathrm{pH}$.

What should also be defined, at least broadly, is the net acid load of the diet, the primary topic of the present paper. Diet net acid load can be estimated from measurements of urinary excretion of ammonium, titratable acids and bicarbonate (called net acid excretion; NAE), or can be calculated from dietary constituents (called net endogenous acid production; NEAP). The techniques for measuring or quantifying the acid load of the diet will be discussed in a later section, but, in general, food contributes a net acid or base effect due to the balance between the acid-forming constituents, such as sulfuric acid produced from the catabolism of methionine and cystine in dietary proteins, and the baseforming constituents, for example, bicarbonate, produced from the metabolism of the $\mathrm{K}$ salts of organic anions in plant foods. As predicted by the Stewart hypothesis, sodium chloride appears to affect systemic acid-base status independently of the net acid load of the diet, perhaps by affecting renal excretion of $\mathrm{Cl}^{-} / \mathrm{NH}_{4}^{+}$, or by a strong ion effect ${ }^{(6)}$. The effects of sodium chloride are especially relevant, given the high salt content of the typical diet in industrialised countries.

With an increasing understanding of acid-base chemistry has come recognition of the significant differences between contemporary diets and diets more typical of Homo sapiens ancestors. Although of course we do not know exactly what our hominid ancestors ate, studies in hunter-gatherer tribes suggest a relatively high intake of plant foods compared with modern-day humans ${ }^{(7)}$. In a recent study estimating the net acid load (NEAP) of 159 hypothetical pre-agricultural diets, $87 \%$ were found to be base producing, with an estimated mean NEAP of negative $88 \mathrm{mEq} / \mathrm{d}$. In comparison, calculations from the US Third National Health and Nutrition Examination Survey (NHANES III) found the average American diet to be acid producing, with an NEAP of positive $48 \mathrm{mEq} / \mathrm{d}^{(8)}$. This represents a switch from the net baseproducing diet we ate for the majority of our evolutionary history to the net acid-producing diet we have been eating for only several thousand years. Much of the current research highlights this change and the potential long-term physiological consequences of a chronic low-grade metabolic acidosis among those eating the typical Western diet, and the effects of reducing or eliminating this diet acid load by altering the diet or giving base supplements.

\section{Is acidosis a real physiological phenomenon?}

The human body tends to maintain a tightly controlled $\mathrm{pH}$ of about 7.40 in the extracellular fluid by respiratory excretion of carbon dioxide and renal excretion of non-carbonic (non-volatile) acid or base ${ }^{(9)}$. Everyday metabolism produces acid as non-volatile sulfate from amino acid catabolism, non-metabolised organic acids and phosphoric and other acids. The kidney reabsorbs all of the filtered bicarbonate $\left(\mathrm{HCO}_{3}^{-}\right)$and generates new bicarbonate in the collecting duct. Under normal steady-state conditions, the net quantity of acid secreted and the consequent renal generation of new bicarbonate equals the rate of metabolic proton generation, preserving $\mathrm{pH}$ balance. In metabolic acidosis, either non-volatile acid accumulates, or $\mathrm{HCO}_{3}^{-}$is lost (for example, in diarrhoea) and this can be happening even when the plasma $\mathrm{HCO}_{3}{ }^{-}$is within the range considered to be normal $(24-28 \mathrm{mmol} / \mathrm{l})^{(10)}$.

While acute acid loading may only temporarily disrupt acid-base equilibrium, a chronic perturbation occurs when metabolism of the diet repeatedly releases non-carbonic acids into the systemic circulation in amounts that exceed the amount of base released concomitantly (for example, bicarbonate from combustion of organic acid salts of $\mathrm{K}$ in vegetable foods $)^{(11)}$. The size of the discrepancy between acid and base production determines the NEAP rate. To maintain equilibrium when there is a net retention of acid $\left(\mathrm{H}^{+}\right)$, at least three compensatory physiological responses are activated: buffering, increased ventilation, and increased renal reabsorption and generation of $\mathrm{HCO}_{3}^{-}$. The major reservoir of base is the skeleton (in the form of alkaline salts of $\mathrm{Ca}$ ) which provides the buffer needed to maintain blood $\mathrm{pH}$ and plasma bicarbonate concentrations. To some degree, skeletal muscle also acts as a buffer ${ }^{(12)}$. Respiratory ventilation increases within minutes if the acidosis is great enough, and the kidneys compensate by increasing $\mathrm{HCO}_{3}^{-}$ reabsorption, $\mathrm{H}^{+}$secretion, and production of the urinary buffer ammonia, all in response to an acidic load.

Thus the loss of bone mass due to acidosis has generally been considered a passive process, a physico-chemical dissolution of the matrix. However, bone dissolution is more than just a passive process, but rather is one of active resorption by osteoclasts, with extracellular $\mathrm{H}^{+}$being a key inducer of osteoclastic activity. Indeed, extracellular $\mathrm{H}^{+}$has been suggested to be the 'long-sought osteoclast activation factor', partly because in vitro experiments show osteoclasts to be almost inactive at a $\mathrm{pH}$ above $7 \cdot 4$, with $\mathrm{pH}$ reductions of $\leq 0 \cdot 1$ sufficient to cause a doubling of resorption pit formation, removing both mineral and organic components of bone ${ }^{(13)}$. A number of in vitro studies have shown that even very small changes in $\mathrm{pH}$ have an effect especially on osteoclastic resorptive activity and on osteoblastic activity, with acidosis exerting a selective, inhibitory action on matrix mineralisation ${ }^{(14-16)}$. Most recently, Frick et al. have demonstrated that ovarian cancer $G$ protein-coupled receptor-1 (OGR1) is the proton-sensing receptor on the osteoblast that leads to osteoclast activation ${ }^{(17)}$.

In vivo studies have generally supported the in vitro findings that acid-promoting diets are associated with both increased $\mathrm{Ca}$ and increased bone matrix protein excretion (used as a marker for estimating bone loss), and that neutralising the acid intake with diet or bicarbonate supplements decreases urine $\mathrm{Ca}$ and bone matrix protein excretion ${ }^{(18-21)}$. In a trial of 170 postmenopausal women, for example, potassium bicarbonate supplementation reduced daily urinary $\mathrm{Ca}$ excretion, and one could predict which women would benefit most - those with the greatest urinary Ca loss ${ }^{(22)}$.

Additionally, the same mechanism may be involved in $\mathrm{Ca}$ nephrolithiasis ${ }^{(23-25)}$. A common risk factor for $\mathrm{Ca}$ stone formation appears to be hypocitraturia, which has been 
associated with a low urinary $\mathrm{K}$ level and a more acidic urinary $\mathrm{pH}$, both of which can be predicted by dietary intake ${ }^{(26,27)}$. However, it appears that dietary acid load is a better predictor of urinary citrate than the intake of most individual nutrients, including dietary K. In a trial of 187 patients with renal $\mathrm{Ca}$ stone disease, an inverse correlation $(-0 \cdot 18)$ was found between daily potential renal acid load (PRAL; defined below) and daily urinary citrate $(P<0 \cdot 01)$. PRAL was also inversely related to urinary $\mathrm{pH}$ and $\mathrm{K}$, and although dietary protein and $\mathrm{K}$ were correlated with citrate excretion, these relationships did not reach statistical significance ${ }^{(28)}$. A low-salt, low-animal protein diet has also been shown to reduce risk of stone recurrence (relative risk 0.49 ) with men followed over 5 years ${ }^{(27)}$. While there are several possible explanations for this effect, one is that the reduced salt and/or animal protein diet is likely to result in a lower acid load.

Finally, metabolic acidaemia has been associated with increased protein breakdown in rats ${ }^{(29)}$ and possibly subjects with end-stage renal disease ${ }^{(30)}$. Mitch et al. demonstrated that increased activation of a ubiquitin-proteasome pathway (via an insulin- or insulin-like growth factor-1-mediated transporter ${ }^{(31)}$ ) increases the production of amino acids which are then made into glutamate in the liver, transported to the proximal renal tubular cells, and then excreted as ammonia $\left(\mathrm{NH}_{3}\right)$ and complexed to $\mathrm{H}^{+(29)}$. This mechanism allows the kidneys to dramatically increase the amount of acid excreted daily.

(a)

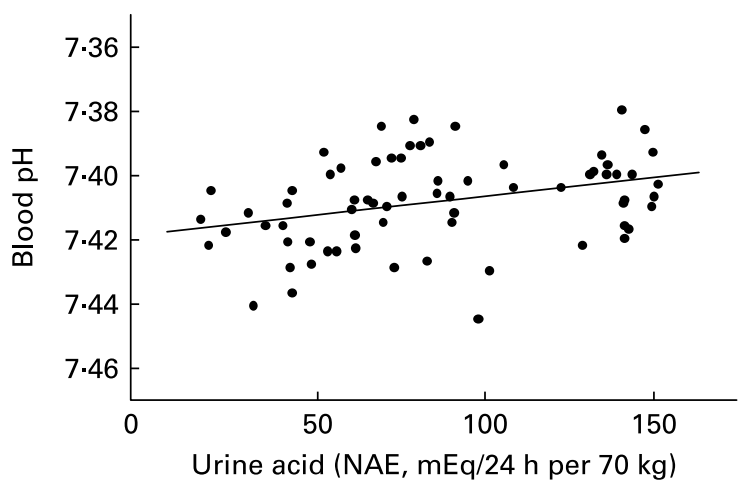

(c)

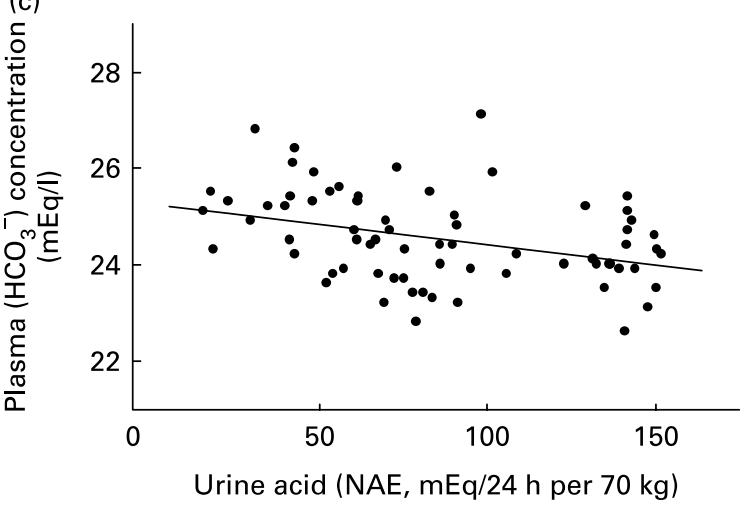

\section{What are the causes of acidosis?}

The causes of metabolic acidosis include increased consumption or generation of organic acids, as well as either insufficient production of bicarbonate, or renal and/or gastrointestinal loss of bicarbonate, such as that seen in renal disease, diarrhoea, pancreatic drainage and biliary fistula. Causes of renal tubular acidosis include Sjögren's syndrome, systemic lupus erythematosus, urinary tract obstruction, fever, aldosterone deficiency and glucocorticoid administration $^{(10)}$. Many of these medical conditions are typically associated with overt laboratory abnormalities; either a frank acidaemia, a decrease in plasma bicarbonate, or an increase in the anion gap.

In comparison, diet-induced 'low-grade' metabolic acidosis has only very small decreases in blood $\mathrm{pH}$ and plasma bicarbonate within the range considered to be normal. Within that range, this means that the system equilibrates nearer the lower end of normal rather than the higher end of normal (see Fig. 1). But, if the duration of the acidosis is prolonged or chronically present, even a low degree of acidosis becomes significant. This less severe but more chronic 'low-grade' acidosis is thought to be brought about primarily by two factors: advancing age with a consequent decline in renal function, and diet, which may promote acidosis by both its net acid load, as well as its sodium chloride content. With age, the severity of diet-dependent acidosis increases independently of the diet, most likely due

(b)

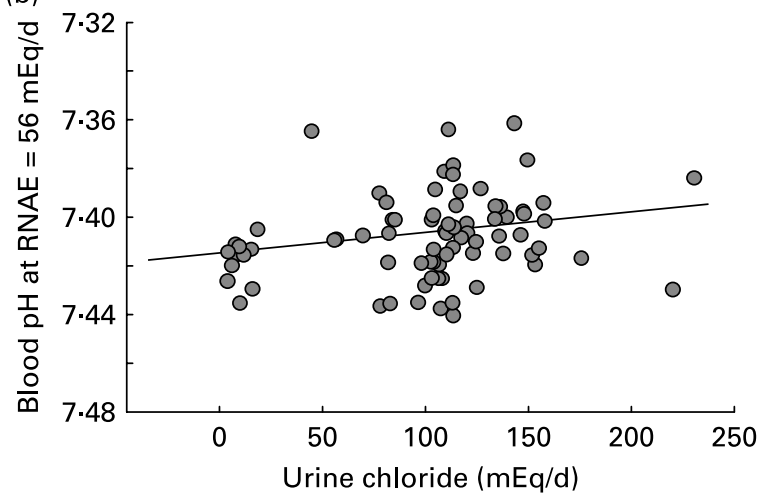

(d)

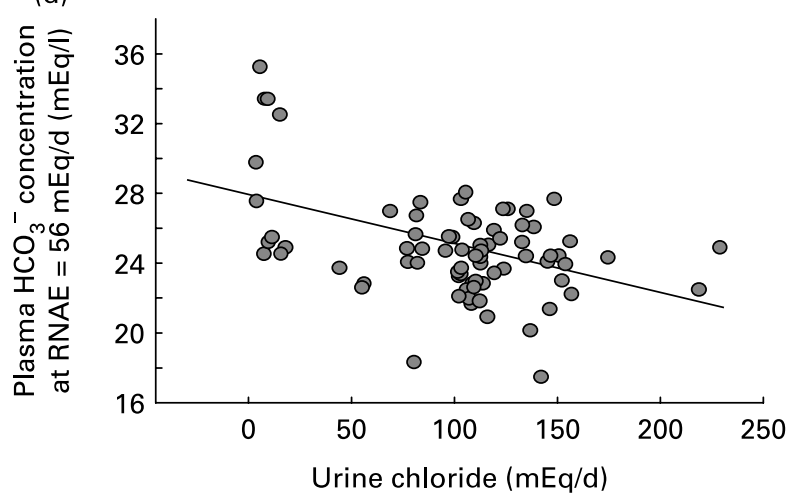

Fig. 1. (a) Blood $\mathrm{pH}$ at constant net acid excretion (NAE) rate $(r 0.34 ; P<0.005)$. (b) Blood pH at constant urinary chloride excretion rate (renal NAE (RNAE) $=56 \mathrm{mEq} / \mathrm{d})(r 0.22 ; P<0.05)$. (c) Plasma bicarbonate at constant NAE rate $(r-0.36 ; P<0.005)$. (d) Plasma bicarbonate at constant urinary chloride excretion rate $(\mathrm{RNAE}=56 \mathrm{mEq} / \mathrm{d})(r-0.45 ; P<0.001)$. Adapted from Frassetto et al. ${ }^{(6)}$. 
Table 1. Algorithms to determine net endogenous acid production (NEAP)

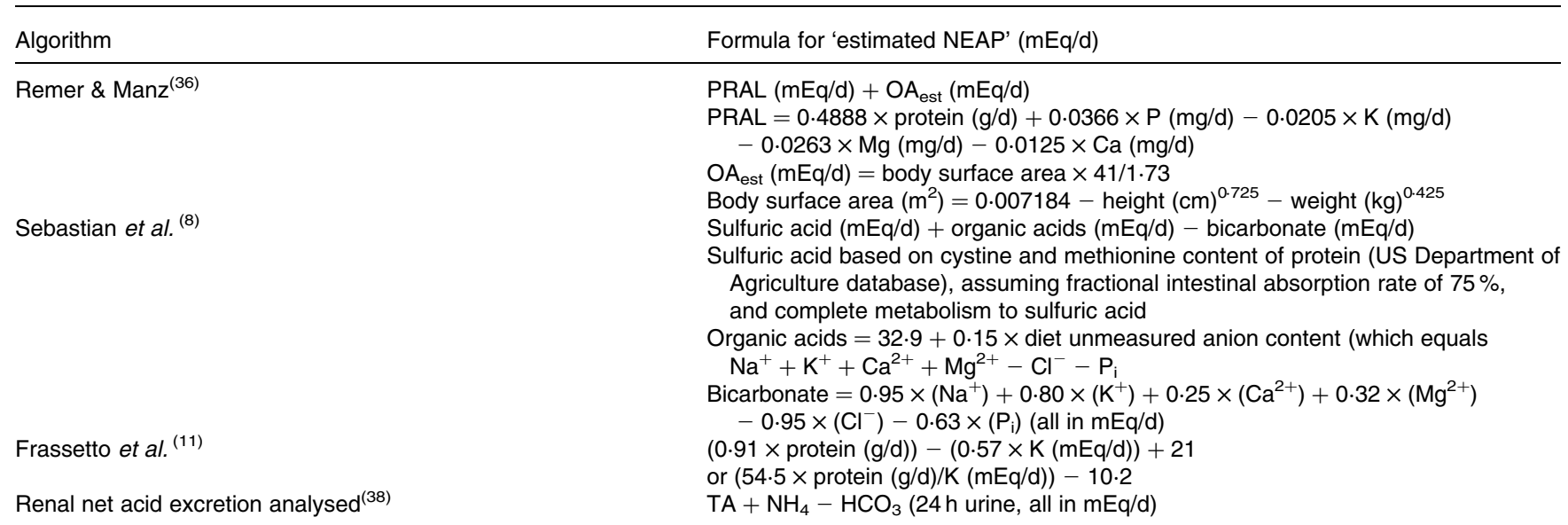

PRAL, potential renal acid load; $\mathrm{OA}_{\text {est }}$, organic acids estimated; $\mathrm{P}_{\mathrm{i}}$, inorganic $\mathrm{P} ; \mathrm{TA}$, titratable.

to a decline in kidney functional capacity with age ${ }^{(20,32,33)}$. Renal insufficiency contributes to a metabolic acidosis by reducing conservation of filtered bicarbonate and excretion of acid.

Diet's contribution to an acidotic state is now well documented. In the European Prospective Investigation into Cancer and Nutrition (EPIC) study of over 22000 men and women, after adjusting for age, BMI, physical activity and smoking, a more alkaline diet (as calculated by PRAL (a diet-only-based estimate of the production of endogenous acid) was significantly associated with a more alkaline urine, both before and after adjustment for age, physical activity and smoking, and after exclusion for urinary protein, glucose and ketones, and for those diagnosed with high blood pressure and/or diuretic medication use (all factors known to influence urine $\mathrm{pH})^{(34)}$.

\section{How is acidosis diagnosed?}

Several approaches have been used to estimate the acid-base equilibrium of the body, as well as the net acid contribution from the diet. As discussed previously, this is an area without general consensus, and one that lacks a definitive marker of acid-base status. Because plasma $\mathrm{pH}$ is so tightly regulated, without acidaemia an acidosis may not be detected, despite the stress on the body's buffering capacity. Additionally, it has been shown that plasma bicarbonate level may be normal even when acidosis is present, and so neither plasma bicarbonate nor the serum anion gap is a sensitive indicator of acidosis ${ }^{(10,35)}$. This situation is analogous to the impaired glucose tolerance that precedes frank blood sugar elevation. Waiting for acidaemia before recognising acidosis is not a sound clinical strategy.

NEAP represents the amount of net acid (acid minus base) produced by the metabolic system every day (i.e. a combination of cellular metabolism and exogenous acid and base loads from the diet). NEAP can either be measured by quantifying the inorganic constituents of diet, urine and stool, and of the total organic anion content of the urine (calculated as the sum of urinary inorganic sulfate and organic acid salts minus dietary organic anions less faecal organic anions) ${ }^{(1)}$, or from estimations of acid or base production from the constituents of the diet. Several methodologies have been proposed to estimate NEAP from dietary components $^{(11,36,37)}$. To avoid confusion, when the NEAP is estimated (which it usually is), it is identified as 'estimated NEAP', and the algorithm used for the estimation clearly specified (see Table 1) ${ }^{(38)}$.

The net amount of acid produced daily (NEAP) is closely tied to the net amount of acid excreted (NAE) by the kidneys daily. NAE can also be measured by quantifying the amount of acids in the form of ammonium and titratable acid in the urine and subtracting the amount of base (bicarbonate) ${ }^{(34)}$. When measured directly, nearly $90 \%$ of the variance in renal NAE among subjects is accounted for by differences in NEAP, and because of this closeness in value, they are often considered equivalent ${ }^{(20)}$.

Another test often used to estimate the NEAP is the $24 \mathrm{~h}$ urine $\mathrm{pH}$. Urinary $\mathrm{pH}$ represents an index of the dietdependent NAE (correlation with calculated NAE, $r$ 0.83; $P<0.001)^{(39)}$, as well as the PRAL ${ }^{(34,40)}$. Additionally, urine $\mathrm{pH}$ can be adjusted to a target $\mathrm{pH}$ based on PRAL calculations for dietary intake. However, $\mathrm{pH}$ strip measurement of the first voided urine was not found to be predictive of the NEAP reflected by the $24 \mathrm{~h}$ urine $\mathrm{NAE}^{(41)}$.

Lastly, while urinary $\mathrm{Ca}$ is not considered a specific marker for acid-base equilibrium, it has been used as a marker of bone turnover, and elevated levels are a risk factor for kidney stone formation ${ }^{(42-45)}$. As discussed below, it does not necessarily indicate increased bone $\mathrm{Ca}$ loss, however. It could, for example, represent a change in intestinal absorption.

In summary, analysed NAE appears to be the closest approximation of 'true' NEAP, and is more easily determined. For simplicity, however, various computational models for estimating NEAP are often employed, each with its own advantages and disadvantages (see Table 1). For a more complete discussion of the pros and cons for each methodology, the reader is referred to a recent review ${ }^{(46)}$.

\section{How is acidosis normalised?}

The normalisation of a low-grade chronic metabolic acidosis has been accomplished by two methods: change in dietary 
patterns and alkaline supplementation. Dietary factors that affect net acid production include the quantity and type of protein intake, fruits and vegetables and table salt (sodium chloride). Alkali supplementation is generally in the form of potassium or sodium bicarbonate or citrate.

Increased fruit and vegetable consumption, as well as $\mathrm{K}$ and $\mathrm{Mg}$ alkali intake, is consistently associated with a baseproducing diet ${ }^{(47)}$. It has been shown that a vegetarian diet has a considerably lower NEAP than both a high and moderate omnivorous protein intake ${ }^{(36)}$.

Reducing protein consumption down to the US dietary recommended intake in a trial of thirty-nine healthy premenopausal women has also been shown to reduce $\mathrm{Ca}$ excretion and raise urinary $\mathrm{pH}$, as well as reduce markers of bone resorption $^{(48)}$. It should be emphasised that this trial did not evaluate a low-protein diet, but rather lowered what could be considered a high protein intake to a level of $0.8 \mathrm{~g} / \mathrm{kg}$ for this population. Because renal $\mathrm{NH}_{4}^{+}$formation is dependent upon adequate protein intake, an extremely protein-deficient diet may also increase acidosis ${ }^{(49)}$. In fact, in a recent study of 161 postmenopausal women, protein intake had a positive association with lumbar bone mineral density, but only after adjusting for the negative effect of the sulfur content of the protein (sulfate), perhaps 'reconciling reports of positive impacts of dietary protein on bone health with reports of a negative impact of the acid load from sulfur-containing amino acids ${ }^{(50)}$. In children, a greater protein intake has been associated with greater bone strength, though this effect is negated if alkalinising nutrients are lacking. It should be noted, however, that clearly bone may be influenced by these minerals in ways unrelated to acid-base chemistry ${ }^{(51)}$.

Finally, increasing sodium chloride intake dose-dependently decreases blood $\mathrm{pH}$ and plasma bicarbonate levels ${ }^{(52)}$, independent of the partial pressure of carbon dioxide $\left(\mathrm{P}_{\mathrm{CO} 2}\right)$, creatinine clearance and dietary acid load ${ }^{(6)}$. This effect may be due to a decrease in the strong ion difference, as total chloride concentration increases relative to total $\mathrm{Na}$ concentration, an effect that may increase $\mathrm{H}^{+}$concentration ${ }^{(53)}$. Subjects who are particularly sensitive to salt, generally defined as an increase of 3 to $5 \mathrm{mmHg}$ for a given salt load, have more of a metabolic acidosis than those subjects who are salt resistant ${ }^{(54)}$. So, while everyone's net acid load would improve by lowering their dietary salt intake, some individuals should benefit more than others from this dietary intervention.

A number of supplemental interventions have also been used. Salts of carbonic acid are available in a variety of formats. These include sodium or potassium bicarbonate and calcium carbonate. Alkali salts are also available as citrate, acetate or hydroxides. As suggested above, giving $\mathrm{Na}$ salts may be partly counterproductive, given their other effects, and so most studies use $\mathrm{K}$ or $\mathrm{Ca}$ alkali salts. These salts dose-dependently decrease $\mathrm{NAE}^{(55,56)}$.

Caution using alkali therapy without careful consideration and expertise in subjects with heart, lung or kidney disease is needed. In congestive heart failure, sodium bicarbonate impairs arterial oxygenation and reduces systemic and myocardial oxygen consumption in these patients, which may lead to transient myocardial ischaemia ${ }^{(57)}$. Additionally there may be several simultaneous processes affecting acidbase status among patients with congestive heart failure ${ }^{(58)}$.
Similarly, bicarbonate loading may worsen exercise response in chronic obstructive pulmonary disease patients ${ }^{(59)}$. Finally, subjects with kidney failure may develop elevated blood $\mathrm{K}$ levels and potentially fatal cardiac arrhythmias if given $\mathrm{K}$ alkali salts, or volume overload and breathing problems if given $\mathrm{Na}$ alkali salts.

\section{Is acidosis clinically relevant?}

Finally, from a clinical standpoint, the most important question is whether or not acidosis has pathophysiological effects that could be ameliorated or abolished by reversing the acidosis. These detrimental effects are associated with long-term acidosis (years to decades), and offer significant potential for prevention-based interventions. Areas of recent interest on the effects of chronic low-grade metabolic acidosis include effects on bone, muscle and kidney stone formation. While the data are generally consistent for the effects of alkali salts on urine $\mathrm{Ca}$, bone biomarker or urinary $\mathrm{N}$ excretion (that is, shorter-term effects), the data are less consistent for the longer-term effects of alkali salts on bone mineral density, muscle function or fracture incidence. Positive correlations have been demonstrated using epidemiological or cohort studies, but results of prospective, randomised, placebocontrolled studies on long-term outcomes are mixed.

\section{Bone}

In an examination of over 1000 women between the ages of 45 and 54 years, a lower dietary intake of acid-producing foods correlated with greater spine and hip bone mineral density, as well as greater forearm bone mass, after adjusting for age, weight, height and menstrual status ${ }^{(60)}$. In the Study of Osteoporotic Fractures Research cohort, over 1000 women aged $65+$ years were enrolled in a prospective cohort study. Those with a high dietary ratio of animal to vegetable protein intake (a marker for a greater NEAP) were found to have more rapid femoral neck bone loss and a greater risk of hip fracture than did those with a low ratio ${ }^{(61)}$.

A number of trials have shown that the bone loss can be reversed by the addition of a base ${ }^{(21)}$. Potassium bicarbonate has been shown to improve $\mathrm{Ca}$ and $\mathrm{P}$ balance, reduce bone resorption rates, and mitigate the normally occurring agerelated decline in growth hormone secretion ${ }^{(20)}$. Potassium citrate combined with calcium citrate may be more beneficial than either alone, as demonstrated in a cross-over trial on bone turnover in postmenopausal women ${ }^{(62)}$. Urinary $\mathrm{Ca}$ excretion and markers of bone health were improved with potassium citrate, more so in those consuming a high-Na diet ${ }^{(63)}$. A recent randomised cross-over trial enrolled postmenopausal women, and introduced four well-controlled diets with varying amounts of calcium and sodium chloride, and evaluated bone $\mathrm{Ca}$ balance. They found that at low $\mathrm{Ca}$ intakes, the bone $\mathrm{Ca}$ balance was negative at varying degrees of sodium chloride intake, but at high $\mathrm{Ca}$ intakes, a positive balance was only seen when $\mathrm{Na}$ intake was low ${ }^{(64)}$. Similarly, in a trial of men with step-wise increases in sodium chloride intake, indications of increased bone resorption and metabolic acidosis were seen with increasing salt intake, and a change in blood $\mathrm{pH}$ change averaging approximately $0 \cdot 02^{(52)}$. 
In a prospective, controlled, trial, 109 men and women with kidney stones had a bone mass increase by increasing their daily alkali intake (potassium citrate), an effect attributed directly to alkalinisation because urinary $\mathrm{Ca}$ excretion did not change ${ }^{(65)}$. Another prospective, blinded study using potassium citrate in 161 postmenopausal women also demonstrated an increase in bone mass over a 12-month period. The authors concluded that 'as a proof-of-principle study, it demonstrates that neutralization of diet-induced endogenous acid production increases BMD (bone mineral density), thereby proving the concept that such dietary acid loads are detrimental to bone mass and thus constitute a causative risk factor for bone loss in postmenopausal women with osteopenia' ${ }^{(66)}$.

On the other hand, a recent prospective randomised placebocontrolled trial by MacDonald et al. did not demonstrate a difference in bone mineral density by dual-energy X-ray absorptiometry after 2 years of potassium citrate supplementation of either 55.5 or $18.5 \mathrm{mEq} / \mathrm{d}$, or an increase in fruit and vegetable intake by $300 \mathrm{~g}$ compared with placebo in 276 postmenopausal women ${ }^{(67)}$. Interestingly though, they found a significant correlation between the amount of fruit eaten at baseline and bone mineral density at the hip in the entire cohort. And the authors report that 'food diaries and checklists suggested good compliance for most women, but the blood measurements [plasma vitamin $\mathrm{C}$, homocysteine, and whole cell folate] did not corroborate this'.

A recent study suggests that bicarbonate has favourable effects on bone resorption and $\mathrm{Ca}$ excretion compared with $\mathrm{K}$ (as potassium chloride), which calls for greater clarification as to the active component in supplemental therapies ${ }^{(68)}$. Unless Ca-balance studies are performed, rather than just urinary $\mathrm{Ca}$ measurements, it cannot be certain that lower urinary $\mathrm{Ca}$ or a decline in bone markers actually translates into less bone loss. For example, decreased urinary $\mathrm{Ca}$ may be due to reduced $\mathrm{Ca}$ absorption and not due to less bone loss. This point is emphasised in a recent meta-analysis (Fenton et al. ${ }^{(69)}$ ) which found that although there is a linear association between urinary $\mathrm{Ca}$ excretion in response to the changes in NAE, this does not necessarily mean that the increased $\mathrm{Ca}$ in the urine is from bone. However, they did find that over 20 years, the quantity of excess urinary $\mathrm{Ca}$ is consistent with the loss of almost half of skeletal $\mathrm{Ca}$ and severe osteoporosis, though their study did not show causality ${ }^{(69)}$. These same authors published a second metaanalysis which assessed the effect of dietary changes in NAE on urinary $\mathrm{Ca}, \mathrm{Ca}$ balance, and N-telopeptide, which found that a higher NAE does not reflect a net loss of whole body $\mathrm{Ca}^{(70)}$. This analysis had several limitations - the studies included did not directly measure bone health or the progression of osteoporosis, and only studies which modified protein intake were included. Thus, studies which examined the effect of changes in NAE from either bicarbonate salts or altered intakes of fruit and vegetables or grain foods were excluded, and not assessed by this meta-analysis.

\section{Kidney stones}

Also of clinical significance is the role metabolic acidosis plays in nephrolithiasis, and its potential connection to bone loss. Urinary Ca excretion is directly proportional to NAE in both stone-formers and normal subjects ${ }^{(71)}$. In a study of nearly
200 renal stone-formers designed to identify the greatest risk factors for nephrolithiasis, it was the potential acid load of the diet which had the strongest association with stone risk. The authors suggest 'that a diet with a very low potential acid load should be encouraged in renal stone patients for the prevention of recurrent stones. This result can be obtained by the restriction of animal proteins but also by abundant supplementation with vegetables and fruits'(28). Potassiummagnesium citrate has been shown to counter renal stone formation associated with immobilisation and was associated with a significant increase in urinary $\mathrm{pH}^{(72)}$. Though increased urinary $\mathrm{Mg}, \mathrm{pH}$ and citrate are associated with reduced stone formation individually, their effect appears to be greater when used together ${ }^{(73)}$. Potassium bicarbonate is more effective than potassium chloride for preventing stone formation when used with hydrochlorothiazide ${ }^{(74)}$. Potassium citrate is also frequently used, and has been found to reduce bone degradation in stone-formers ${ }^{(65)}$ and reduce urinary $\mathrm{Ca}$ excretion ${ }^{(63)}$. The same may be true of potassium and/or magnesium citrate and for stone prevention - in a trial with normal volunteers and stone-formers, potassium and magnesium citrate together had a greater effect than either individually to reduce the ion activity product index of calcium oxalate ${ }^{(75)}$. Potassiummagnesium citrate was also shown to reduce the risk of calcium oxalate stone formation by $85 \%$ during a 3 -year period in a randomised controlled trial $^{(76)}$, perhaps by correcting hypocitraturia, a known risk factor for forming kidney stones and a factor (as mentioned previously) inversely associated with acid load calculated by PRAL ${ }^{(28)}$.

Unlike in the studies of healthy subjects, in both men and women with a history of forming $\mathrm{Ca}$ stones, a 2-year treatment with potassium citrate increased forearm bone mineral density in idiopathic $\mathrm{Ca}$ stone-formers, with the speculation that it was the alkali load that reduced bone resorption by buffering endogenous acid production ${ }^{(65)}$.

\section{Muscle}

Another area of interest is the use of alkaline therapy for improving muscle function, exercise capacity and reducing age-related muscle wasting. Acidaemia has been shown to increase muscle degradation in patients on haemodialysis ${ }^{(77)}$. One epidemiological study of 384 healthy men and women aged $65+$ years found a higher intake of foods rich in $\mathrm{K}$ (fruits and vegetables) was associated with greater lean muscle mass. The authors speculated that 'this association is likely to result from the fact that the ingestion of potassiumrich alkaline foods such as fruit and vegetables relieves the mild metabolic acidosis that occurs with the ingestion of a typical American diet', and suggest that it is plausible that age-related muscle mass decline and sarcopenia may be prevented by the appropriate intake of alkaline $\mathrm{K}$ salts ${ }^{(78)}$.

Potassium bicarbonate has been shown to neutralise the metabolic acidosis, and reduce urinary $\mathrm{N}$ wasting in postmenopausal women. As faecal $\mathrm{N}$ excretion is typically very low $(<12 \%)$, and unaffected by alkali administration, the authors speculated that this $\mathrm{N}$-sparing may prevent loss of muscle mass, and may even restore past deficits ${ }^{(79)}$. While it cannot be certain that the decrease in $\mathrm{N}$ excretion is directly due to less muscle degradation, it is consistent with previous 
research suggesting that acidosis stimulates muscle proteolysis by activating proteolytic pathways ${ }^{(29)}$.

Whether neutralisation of acidosis improves exercise function is unclear, with studies demonstrating both positive and negative results. Short-term intake of sodium bicarbonate helped reduce the exercise-related drop in $\mathrm{pH}$, improved anaerobic performance in a dose-dependent manner ${ }^{(80)}$, improved intermittent sprint performance ${ }^{(81)}$ and was of ergogenic benefit in the performance of short-term, highintensity work $^{(82)}$. One possible mechanism of action is an increase in plasma $\mathrm{pH}$ at rest, providing a delayed onset of intracellular acidification during exercise ${ }^{(83)}$, or by providing additional bicarbonate for an increased buffering capacity, as concluded in a trial involving sodium bicarbonate ingestion by elite swimmers ${ }^{(84)}$. Other studies have not demonstrated any effect of short-term bicarbonate supplementation ${ }^{(85)}$. Longer-term studies on the effects of alkali neutralisation on muscle function and mass are presently underway (LA Frassetto, personal communication).

\section{Other}

There may also be a connection between insulin resistance and acid-base equilibrium, though this relationship is still speculative. Insulin resistance has been associated with a lower urinary citrate excretion, and hypocitraturic patients show greater insulin resistance than normocitraturic $\mathrm{Ca}$ stone-formers ${ }^{(86)}$. Type 2 diabetes mellitus has been shown to increase the risk of uric acid stone formation, because it causes a lower urinary $\mathrm{pH}$ due to impaired kidney ammoniagenesis ${ }^{(87)}$. This lower urinary $\mathrm{pH}$ cannot be entirely attributed to a greater BMI or acid intake, though both are factors in determining urinary $\mathrm{pH}^{(88)}$. Finally, in an evaluation of 148 adults with no kidney stones, participants with the metabolic syndrome had a significantly lower $24 \mathrm{~h}$ urine $\mathrm{pH}$ than those without, with an incremental reduction in $\mathrm{pH}$ associated with the number of metabolic abnormalities present ${ }^{(89,90)}$.

Also of clinical relevance may be the treatment of pain, although it is less well studied. Local tissue acidosis has been documented in patients with complex regional pain syndrome, and leads to increased pain sensation ${ }^{(91)}$. The mechanism for pain sensation may be mediated by acidsensing ion channels (ASIC), with an increase in ASIC activity in spinal dorsal horn neurons promoting pain by central sensitisation, a mechanism documented in rats ${ }^{(92)}$. ASIC activity may also be induced by $\mathrm{NO}^{(93)}$, and appears to be tightly regulated by $\mathrm{pH}^{(94)}$. This is an area that lacks significant clinical research.

\section{Conclusion}

The lack of consensus for both qualitative and quantitative aspects of acid-base chemistry in physiological systems as well as measurement has caused considerable confusion for both researchers and clinicians. This confusion has also complicated the search for cause and effect and made clinical application difficult and controversial. Nonetheless, the available research makes a compelling case that diet-induced acidosis is a real phenomenon, has significant clinical relevance, may largely be prevented through dietary changes, and should be recognised and treated.
Both dietary interventions (lowering protein and increasing fruit and vegetable consumption) and nutritional supplementation (with $\mathrm{K}$ and $\mathrm{Mg}$ salts) have been shown to normalise acidosis, but with discordant results on whether this is then associated with clinical improvement in bone, muscle or other physiological or pathophysiological conditions. A positive NEAP diet results in increased urine $\mathrm{Ca}, \mathrm{N}$ and bone marker excretion, and predisposes to kidney stones. Whether or not, over the longer term, this translates to lower bone density, increased bone and muscle loss with ageing is unclear and requires further investigation.

\section{Acknowledgements}

The present review was supported by partial funding from pH Sciences (Seattle, WA, USA).

L. A. F. would like to acknowledge Anthony Sebastian and R. Curtis Morris Jr, the two people she has worked with for all of these years, who are responsible for the ideas behind what she does.

J. P. and J. K. were responsible for data review and writing of the initial manuscript. L. A. F. provided critical review and editing of several drafts, and participated in final manuscript writing.

\section{References}

1. Lennon EJ, Lemann J Jr \& Litzow JR (1966) The effects of diet and stool composition on the net external acid balance of normal subjects. J Clin Invest 45, 1601-1607.

2. Goodman AD, Lemann J Jr, Lennon EJ, et al. (1965) Production, excretion, and net balance of fixed acid in patients with renal acidosis. J Clin Invest 44, 495-506.

3. Kurtz I, Kraut JA, Ornekian V, et al. (2008) Acid-base analysis: a critique of the Stewart and bicarbonate-centered approaches. Am J Physiol Renal Physiol 294, F1009-F1031.

4. Manz F (2001) History of nutrition and acid-base physiology. Eur J Nutr 40, 189-199.

5. Story DA (2004) Bench-to-bedside review: a brief history of clinical acid-base. Crit Care 8, 253-258.

6. Frassetto LA, Morris RC Jr \& Sebastian A (2007) Dietary sodium chloride intake independently predicts the degree of hyperchloremic metabolic acidosis in healthy humans consuming a net acid-producing diet. Am J Physiol Renal Physiol 293, F521-F525.

7. Cordain L, Miller JB, Eaton SB, et al. (2000) Plant-animal subsistence ratios and macronutrient energy estimations in worldwide hunter-gatherer diets. Am J Clin Nutr 71, 682-692.

8. Sebastian A, Frassetto LA, Sellmeyer DE, et al. (2002) Estimation of the net acid load of the diet of ancestral preagricultural Homo sapiens and their hominid ancestors. Am J Clin Nutr 76, 1308-1316.

9. Paulev PE \& Zubieta-Calleja GR (2005) Essentials in the diagnosis of acid-base disorders and their high altitude application. J Physiol Pharmacol 56, Suppl. 4, 155-170.

10. Gluck SL (1998) Acid-base. Lancet 352, 474-479.

11. Frassetto LA, Todd KM, Morris RC Jr, et al. (1998) Estimation of net endogenous noncarbonic acid production in humans from diet potassium and protein contents. Am J Clin Nutr 68, 576-583.

12. Bailey JL, England BK, Long RC, et al. (1996) Influence of acid loading, extracellular $\mathrm{pH}$ and uremia on intracellular $\mathrm{pH}$ in muscle. Miner Electrolyte Metab 22, 66-68.

13. Arnett TR (2008) Extracellular $\mathrm{pH}$ regulates bone cell function. J Nutr 138, 415S-418S. 
14. Brandao-Burch A, Utting JC, Orriss IR, et al. (2005) Acidosis inhibits bone formation by osteoblasts in vitro by preventing mineralization. Calcif Tissue Int 77, 167-174.

15. Bushinsky DA (1996) Metabolic alkalosis decreases bone calcium efflux by suppressing osteoclasts and stimulating osteoblasts. Am J Physiol 271, F216-F222.

16. Bushinsky DA (1996) Stimulated osteoclastic and suppressed osteoblastic activity in metabolic but not respiratory acidosis. Am J Physiol 268, C80-C88.

17. Frick KK, Krieger NS, Nehrke K, et al. (2009) Metabolic acidosis increases intracellular calcium in bone cells through activation of the proton receptor OGR1. J Bone Miner Res $\mathbf{2 4}$, 305-313.

18. Buclin T, Cosma M, Appenzeller M, et al. (2001) Diet acids and alkalis influence calcium retention in bone. Osteoporos Int $\mathbf{1 2}$, 493-499.

19. Yancy WS Jr, Olsen MK, Dudley T, et al. (2007) Acid-base analysis of individuals following two weight loss diets. Eur $J$ Clin Nutr 61, 1416-1422.

20. Frassetto L, Morris RC Jr, Sellmeyer DE, et al. (2001) Diet, evolution and aging - the pathophysiologic effects of the post-agricultural inversion of the potassium-to-sodium and base-to-chloride ratios in the human diet. Eur J Nutr 40, 200-213.

21. Sebastian A, Harris ST, Ottaway JH, et al. (1994) Improved mineral balance and skeletal metabolism in postmenopausal women treated with potassium bicarbonate. $N$ Engl J Med 330, 1776-1781.

22. Frassetto L, Morris RC Jr \& Sebastian A (2005) Long-term persistence of the urine calcium-lowering effect of potassium bicarbonate in postmenopausal women. $J$ Clin Endocrinol Metab 90, 831-834.

23. Osther PJ (2006) Effect of acute acid loading on acidbase and calcium metabolism. Scand J Urol Nephrol 40, $35-44$.

24. Caudarella R, Vescini F, Buffa A, et al. (2003) Bone mass loss in calcium stone disease: focus on hypercalciuria and metabolic factors. J Nephrol 16, 260-266.

25. Osther PJ, Bollerslev J, Hansen AB, et al. (1993) Pathophysiology of incomplete renal tubular acidosis in recurrent renal stone formers: evidence of disturbed calcium, bone and citrate metabolism. Urol Res 21, 169-173.

26. Domrongkitchaiporn S, Stitchantrakul W \& Kochakarn W (2006) Causes of hypocitraturia in recurrent calcium stone formers: focusing on urinary potassium excretion. Am J Kidney Dis 48, 546-554.

27. Borghi L, Schianchi T, Meschi T, et al. (2002) Comparison of two diets for the prevention of recurrent stones in idiopathic hypercalciuria. $N$ Engl J Med 346, 77-84.

28. Trinchieri A, Lizzano R, Marchesotti F, et al. (2006) Effect of potential renal acid load of foods on urinary citrate excretion in calcium renal stone formers. Urol Res 34, 1-7.

29. Mitch WE, Medina R, Grieber S, et al. (1994) Metabolic acidosis stimulates muscle protein degradation by activating the adenosine triphosphate-dependent pathway involving ubiquitin and proteasomes. J Clin Invest 93, 2127-2133.

30. Papadoyannakis NJ, Stefanidis CJ \& McGeown M (1984) The effect of the correction of metabolic acidosis on nitrogen and potassium balance of patients with chronic renal failure. Am J Clin Nutr 40, 623-627.

31. Du J \& Mitch WE (2005) Identification of pathways controlling muscle protein metabolism in uremia and other catabolic conditions. Curr Opin Nephrol Hypertens 14, 378-382.

32. Kraut JA \& Madias NE (2007) Serum anion gap: its uses and limitations in clinical medicine. Clin J Am Soc Nephrol 2, $162-174$
33. Frassetto LA, Morris RC Jr \& Sebastian A (1996) Effect of age on blood acid-base composition in adult humans: role of age-related renal functional decline. Am $J$ Physiol 271, F1114-F1122.

34. Frassetto L \& Sebastian A (1996) Age and systemic acid-base equilibrium: analysis of published data. J Gerontol A Biol Sci Med Sci 51, B91-B99.

35. Welch AA, Mulligan A, Bingham SA, et al. (2008) Urine pH is an indicator of dietary acid-base load, fruit and vegetables and meat intakes: results from the European Prospective Investigation into Cancer and Nutrition (EPIC)-Norfolk population study. Br J Nutr 99, 1335-1343.

36. Remer T \& Manz F (1994) Estimation of the renal net acid excretion by adults consuming diets containing variable amounts of protein. Am J Clin Nutr 59, 1356-1361.

37. Remer T, Dimitriou T \& Manz F (2003) Dietary potential renal acid load and renal net acid excretion in healthy, free-living children and adolescents. Am J Clin Nutr 77, 1255-1260.

38. Frassetto LA, Lanham-New SA, Macdonald HM, et al. (2007) Standardizing terminology for estimating the dietdependent net acid load to the metabolic system. J Nutr 137, $1491-1492$.

39. Remer T \& Manz F (1995) Potential renal acid load of foods and its influence on urine pH. J Am Diet Assoc 95, 791-797.

40. Michaud DS, Troiano RP, Subar AF, et al. (2003) Comparison of estimated renal net acid excretion from dietary intake and body size with urine pH. $J$ Am Diet Assoc 103, 1001-1007.

41. Whiting SJ \& Muirhead JA (2005) Measurement of net acid excretion by use of paper strips. Nutrition 21, 961-963.

42. Jajoo R, Song L, Rasmussen H, et al. (2006) Dietary acid-base balance, bone resorption, and calcium excretion. J Am Coll Nutr 25, 224-230.

43. Pietschmann F, Breslau NA \& Pak CY (1992) Reduced vertebral bone density in hypercalciuric nephrolithiasis. $J$ Bone Miner Res 7, 1383-1388.

44. Stitchantrakul W, Kochakarn W, Ruangraksa C, et al. (2007) Urinary risk factors for recurrent calcium stone formation in Thai stone formers. J Med Assoc Thai 90, 688-698.

45. Damasio B, Massarino F, Durand F, et al. (2005) Prevalence of fasting hypercalciuria associated with increased citraturia in the ambulatory evaluation of nephrolithiasis. J Nephrol 18, 262-266.

46. Frassetto LA, Morris RC Jr \& Sebastian A (2006) A practical approach to the balance between acid production and renal acid excretion in humans. J Nephrol 19, Suppl. 9, S33-S40.

47. Tucker KL, Hannan MT, Chen H, et al. (1999) Potassium, magnesium, and fruit and vegetable intakes are associated with greater bone mineral density in elderly men and women. Am J Clin Nutr 69, 727-736.

48. Ince BA, Anderson EJ \& Neer RM (2004) Lowering dietary protein to U.S. recommended dietary allowance levels reduces urinary calcium excretion and bone resorption in young women. J Clin Endocrinol Metab 89, 3801-3807.

49. Remer T (2001) Influence of nutrition on acid-base balance metabolic aspects. Eur J Nutr 40, 214-220.

50. Thorpe M, Mojtahedi MC, Chapman-Novakofski $\mathrm{K}$, et al. (2008) A positive association of lumbar spine bone mineral density with dietary protein is suppressed by a negative association with protein sulfur. $J$ Nutr 138, 80-85.

51. Alexy U, Remer T, Manz F, et al. (2005) Long-term protein intake and dietary potential renal acid load are associated with bone modeling and remodeling at the proximal radius in healthy children. Am J Clin Nutr 82, 1107-1114.

52. Frings-Meuthen P, Baecker N \& Heer M (2008) Low-grade metabolic acidosis may be the cause of sodium chlorideinduced exaggerated bone resorption. J Bone Miner Res 23, $517-524$. 
53. Kellum JA (2000) Determinants of blood $\mathrm{pH}$ in health and disease. Crit Care 4, 6-14.

54. Sharma AM, Kribben A, Schattenfroh S, et al. (1990) Salt sensitivity in humans is associated with abnormal acid-base regulation. Hypertension 16, 407-413.

55. Lemann J Jr, Gray RW \& Pleuss JA (1989) Potassium bicarbonate, but not sodium bicarbonate, reduces urinary calcium excretion and improves calcium balance in healthy men. Kidney Int 35, 688-695.

56. Frassetto L, Morris RC Jr \& Sebastian A (2004) Diet acid load and bone health. In Nutritional Aspects of Osteoporosis, 2nd ed., chapter 22, pp. 273-290 [P Burckhardt and B Dawson-Hughes, editors]. San Diego, CA: Academic Press.

57. Bersin RM, Chatterjee K \& Arieff AI (1989) Metabolic and hemodynamic consequences of sodium bicarbonate administration in patients with heart disease. Am J Med 87, 7-14.

58. Frangiosa A, De Santo LS, Anastasio P, et al. (2006) Acidbase balance in heart failure. J Nephrol 19, Suppl. 9, S115-S120.

59. Coppoolse R, Barstow TJ, Stringer WW, et al. (1997) Effect of acute bicarbonate administration on exercise responses of COPD patients. Med Sci Sports Exerc 29, 725-732.

60. New SA, MacDonald HM, Campbell MK, et al. (2004) Lower estimates of net endogenous non-carbonic acid production are positively associated with indexes of bone health in premenopausal and perimenopausal women. Am J Clin Nutr 79, $131-138$.

61. Sellmeyer DE, Stone KL, Sebastian A, et al. (2001) A high ratio of dietary animal to vegetable protein increases the rate of bone loss and the risk of fracture in postmenopausal women. Study of Osteoporotic Fractures Research Group. Am J Clin Nutr 73, $118-122$.

62. Sakhaee K, Maalouf NM, Abrams SA, et al. (2005) Effects of potassium alkali and calcium supplementation on bone turnover in postmenopausal women. J Clin Endocrinol Metab 90, $3528-3533$.

63. Sellmeyer DE, Schloetter M \& Sebastian A (2002) Potassium citrate prevents increased urine calcium excretion and bone resorption induced by a high sodium chloride diet. J Clin Endocrinol Metab 87, 2008-2012.

64. Teucher B, Dainty JR, Spinks CA, et al. (2008) Sodium and bone health: the impact of moderately high and low salt intakes on calcium metabolism in postmenopausal women. J Bone Miner Res 23, 1477-1485.

65. Vescini F, Buffa A, La Manna G, et al. (2005) Long-term potassium citrate therapy and bone mineral density in idiopathic calcium stone formers. J Endocrinol Invest 28, 218-222.

66. Jehle S, Zanetti A, Muser J, et al. (2006) Partial neutralization of the acidogenic Western diet with potassium citrate increases bone mass in postmenopausal women with osteopenia. J Am Soc Nephrol 17, 3213-3222.

67. Macdonald HM, Black AJ, Aucott L, et al. (2008) Effect of potassium citrate supplementation or increased fruit and vegetable intake on bone metabolism in healthy postmenopausal women: a randomized controlled trial. Am J Clin Nutr $\mathbf{8 8}$, $465-474$.

68. Dawson-Hughes B, Harris SS, Palermo NJ, et al. (2009) Treatment with potassium bicarbonate lowers calcium excretion and bone resorption in older men and women. J Clin Endocrinol Metab 94, 96-102.

69. Fenton TR, Eliasziw M, Lyon AW, et al. (2008) Meta-analysis of the quantity of calcium excretion associated with the net acid excretion of the modern diet under the acid-ash diet hypothesis. Am J Clin Nutr 88, 1159-1166.

70. Fenton TR, Lyon AW, Eliasziw M, et al. (2009) Meta-analysis of the effect of the acid-ash hypothesis of osteoporosis on calcium balance. J Bone Miner Res 24, 1835-1840.
71. Lemann J Jr (1999) Relationship between urinary calcium and net acid excretion as determined by dietary protein and potassium: a review. Nephron 81, Suppl. 1, 18-25.

72. Zerwekh JE, Odvina CV, Wuermser LA, et al. (2007) Reduction of renal stone risk by potassium-magnesium citrate during 5 weeks of bed rest. $J$ Urol 177, 2179-2184.

73. Schwille PO, Schmiedl A, Herrmann U, et al. (1999) Magnesium, citrate, magnesium citrate and magnesium-alkali citrate as modulators of calcium oxalate crystallization in urine: observations in patients with recurrent idiopathic calcium urolithiasis. Urol Res 27, 117-126.

74. Frassetto LA, Nash E, Morris RC Jr, et al. (2000) Comparative effects of potassium chloride and bicarbonate on thiazideinduced reduction in urinary calcium excretion. Kidney Int $\mathbf{5 8}$, $748-752$.

75. Kato Y, Yamaguchi S, Yachiku S, et al. (2004) Changes in urinary parameters after oral administration of potassiumsodium citrate and magnesium oxide to prevent urolithiasis. Urology 63, 7-12.

76. Ettinger B, Pak CY, Citron JT, et al. (1997) Potassiummagnesium citrate is an effective prophylaxis against recurrent calcium oxalate nephrolithiasis. J Urol 158, 2069-2073.

77. Löfberg E, Gutierrez A, Anderstam B, et al. (2006) Effect of bicarbonate on muscle protein in patients receiving hemodialysis. Am J Kidney Dis 48, 419-429.

78. Dawson-Hughes B, Harris SS \& Ceglia L (2008) Alkaline diets favor lean tissue mass in older adults. Am J Clin Nutr 87, $662-665$.

79. Frassetto L, Morris RC Jr \& Sebastian A (1997) Potassium bicarbonate reduces urinary nitrogen excretion in postmenopausal women. J Clin Endocrinol Metab 82, 254-259.

80. Douroudos F II, atouros IG, Gourgoulis V, et al. (2006) Doserelated effects of prolonged $\mathrm{NaHCO}_{3}$ ingestion during high-intensity exercise. Med Sci Sports Exerc 38, 1746-1753.

81. Bishop D \& Claudius B (2005) Effects of induced metabolic alkalosis on prolonged intermittent-sprint performance. Med Sci Sports Exerc 37, 759-767.

82. McNaughton L, Backx K, Palmer G, et al. (1999) Effects of chronic bicarbonate ingestion on the performance of high-intensity work. Eur J Appl Physiol Occup Physiol 80, $333-336$

83. Raymer GH, Marsh GD, Kowalchuk JM, et al. (2004) Metabolic effects of induced alkalosis during progressive forearm exercise to fatigue. J Appl Physiol 96, 2050-2056.

84. Lindh AM, Peyrebrune MC, Ingham SA, et al. (2008) Sodium bicarbonate improves swimming performance. Int $J$ Sports Med 29, 519-523.

85. Ball D, Greenhaff PL \& Maughan RJ (1996) The acute reversal of a diet-induced metabolic acidosis does not restore endurance capacity during high-intensity exercise in man. Eur J Appl Physiol Occup Physiol 73, 105-112.

86. Cupisti A, Meola M, D’Alessandro C, et al. (2007) Insulin resistance and low urinary citrate excretion in calcium stone formers. Biomed Pharmacother 61, 86-90.

87. Daudon M, Traxer O, Conort P, et al. (2006) Type 2 diabetes increases the risk for uric acid stones. J Am Soc Nephrol 17, 2026-2033.

88. Cameron MA, Maalouf NM, Adams-Huet B, et al. (2006) Urine composition in type 2 diabetes: predisposition to uric acid nephrolithiasis. J Am Soc Nephrol 17, 1422-1428.

89. Maalouf NM, Cameron MA, Moe OW, et al. (2007) Low urine $\mathrm{pH}$ : a novel feature of the metabolic syndrome. Clin J Am Soc Nephrol 2, 883-888.

90. Abate N, Chandalia M, Cabo-Chan JAV Jr, et al. (2004) The metabolic syndrome and uric acid nephrolithiasis: novel features of renal manifestation of insulin resistance. Kidney Int $\mathbf{6 5}$, $386-392$. 
91. Birklein F, Weber M, Ernst M, et al. (2000) Experimental tissue acidosis leads to increased pain in complex regional pain syndrome (CRPS). Pain 87, 227-234.

92. Duan B, Wu LJ, Yu YQ, et al. (2007) Upregulation of acidsensing ion channel ASIC1a in spinal dorsal horn neurons contributes to inflammatory pain hypersensitivity. $J$ Neurosci 27, 11139-11148.
93. Cadiou H, Studer M, Jones NG, et al. (2007) Modulation of acid-sensing ion channel activity by nitric oxide. J Neurosci 27, 13251-13260.

94. Wang WZ, Chu XP, Li MH, et al. (2006) Modulation of acidsensing ion channel currents, acid-induced increase of intracellular $\mathrm{Ca}^{2+}$, and acidosis-mediated neuronal injury by intracellular pH. J Biol Chem 281, 29369-29378. 